\title{
Bax-interacting factor-1 inhibits cell proliferation and promotes apoptosis in prostate cancer cells
}

\author{
LIN XU $^{1-3^{*}}$, ZHU WANG ${ }^{1-3^{*}}$, SHAN-YANG HE ${ }^{4 *}$, SU-FEN ZHANG ${ }^{1-3}$, HONG-JIAO LUO ${ }^{1-3}$, \\ KAI ZHOU ${ }^{1-3}$, XIAO-FEI LI ${ }^{5}$, SHAO-PENG QIU ${ }^{5}$ and KAI-YUAN CAO ${ }^{1-3}$ \\ ${ }^{1}$ Research Center for Clinical Laboratory Standard, Zhongshan School of Medicine, Sun Yat-sen University, \\ Guangzhou 510080; ${ }^{2}$ Key Laboratory of Tropical Disease Control, Ministry of Education, Sun Yat-Sen University, \\ Guangzhou 510080; ${ }^{3}$ Department of Microbiology, Zhongshan School of Medicine, Sun Yat-sen University, \\ Guangzhou 510080; ${ }^{4}$ Department of Obstetrics and Gynecology, The First Affiliated Hospital, \\ Sun Yat-sen University, Guangzhou 510700; ${ }^{5}$ Department of Urology, The First Affiliated Hospital, \\ Sun Yat-sen University, Guangzhou 510080, P.R. China
}

Received April 3, 2016; Accepted August 16, 2016

DOI: $10.3892 / o r .2016 .5172$

\begin{abstract}
Prostate cancer (PCa) is one of the most common malignant tumors and the second leading cause of cancerrelated death among males. Bax-interacting factor-1 (Bif-1) is a member of Endophilin family, which binds to and activates the BAX protein in response to the apoptosis signaling pathway. Loss of Bif-1 may suppress the intrinsic pathway of apoptosis and promote tumorigenesis, but there is also converse evidence that Bif-1 could in part be responsible for the tumorigenesis and the role of Bif-1 in PCa development is not clear. In the present study, we aimed to understand the relationships between Bif-1 expression and PCa development. The mRNA and protein expression levels of Bif-1 in PCa cell lines, benign prostatic hyperplasia $(\mathrm{BPH})(\mathrm{n}=100)$ and PCa tissues $(n=100$, including low Gleason-scored $\mathrm{PCa} n=43$ and high Gleasonscored PCa $n=57$ ) were detected and the effects of Bif-1 overexpression on the apoptosis, proliferation and migration in LNCaP cells were explored. Bif-1 mRNA levels of PCa cell lines were analyzed by real-time PCR and the protein levels were detected by western blotting. Bif-1 expression in BPH and PCa samples was detected by immunohistochemistry. To build Bif-1 overexpression PCa cells, Bif-1 gene was transfected into LNCaP cells by pcDNA3.1(+)-Bif-1 vector. Cell apoptosis was detected by flow cytometric analysis, cell proliferation
\end{abstract}

Correspondence to: Professor Kai-Yuan Cao, Research Center for Clinical Laboratory Standard, Zhongshan School of Medicine, Sun Yat-sen University, 74 Zhongshan Road 2, Guangzhou 510080, P.R. China

E-mail: caoky@mail.sysu.edu.cn

*Contributed equally

Key words: prostate cancer, benign prostatic hypertrophy, Bif-1, cell proliferation, cell apoptosis measured by 3-(4,5-dimethylthiazol-2-yl)-2,5-diphenyltetrazolium bromide (MTT) assay and cell migration was analyzed by wound-healing assay. The results proved that Bif-1 is downregulated in both $\mathrm{PCa}$ cell lines $(\mathrm{P}<0.01)$ and clinical samples $(\mathrm{P}<0.05)$, and Bif-1 expression is suppressed with the cancer progression (BPH vs. PCa $\mathrm{P}<0.01$, and low Gleason-scored $\mathrm{PCa}$ vs. high Gleason-scored $\mathrm{PCa} \mathrm{P}<0.05)$. Overexpression of Bif-1 could significantly inhibit cell proliferation $(\mathrm{P}<0.05)$ and enhancing $\mathrm{PCa}$ cell apoptosis $(\mathrm{P}<0.05)$, but it did not affect the migration ability $(\mathrm{P}>0.05)$. Our findings give strong evidence that Bif-1 is involved in PCa tumorigenesis and acts as a suppressor in PCa progression, and may have significance in understanding the process of PCa development.

\section{Introduction}

Prostate cancer ( $\mathrm{PCa}$ ) is one of the most common malignant tumors in the male worldwide, and the second leading cause of cancer-related death among men in America (1-4). Despite the development in PCa early diagnosis and treatment methods (5), metastasis and tumor relapse still remains a serious problem for the patients long-term survival, and the mechanisms involved in PCa progression and metastasis are not fully understood. Several studies have shown that inhibition of apoptosis is the most critical factor for tumorigenesis in $\mathrm{PCa}(6,7)$. It has been reported that overexpression of $\mathrm{Bcl}-\mathrm{xL}$ in PCa may suppress the activity of the pro-apoptotic molecules Bax and Bak, and may contribute to androgen deprivation resistance and progression of PCa (8-11). However, apoptosis regulation is a very complicated process, with many different signal pathways and molecules involved, therefore, to better understand the anti-apoptosis mechanisms of PCa cells, more apoptosis-related molecules that possibly are involved in the $\mathrm{PCa}$ progression remains to be explored.

Bax-interacting factor-1 (Bif-1), also known as SH3GLB1 or endophilin B1, is a member of Endophilin family, contains an amino-terminal N-BAR (Bin-Amphiphysin-Rvs) domain and a carboxy-terminal SH3 (Src-homology 3) domain and 
displays membrane binding and extension activities (12-14). Bif-1 was originally identified as a Bax-binding protein, and represents a new type of Bax activator that controls the mitochondrial pathway of apoptosis. However, the role of Bif-1 in tumor development and progression remains to be elucidated. Various results seem even contradictory. It is reported in PIN that, knockout of Bif-1 could suppress Bax/Bak conformational change, cytochrome $c$ release, caspase activation and cell death $(8,15-17)$. However, it is also reported that in hepatocellular carcinoma, Bif-1 expression is upregulated and correlates with shortened patient survival (18). There are studies suggested that Bif-1 gene may act as a tumor suppressor (16,19-21). It is reported that Bif-1 mRNA levels are downregulated in lung carcinoma (22), pancreatic $(16,23)$, breast $(20,24)$ and colon cancer (24-26). However, a study in Merkel cell carcinoma (MCC) shows that the Bif-1 expression level is associated with low levels of Bax, which indicated that upregulation of Bif-1 could in part be responsible for the tumorigenesis of MCC (13). There is scarce information concerning the relationships between Bif-1 and PCa. The role of Bif-1 in PCa tumorigenesis and progression remains unclear. A study by Coppola et al (8) found that Bif-1 expression was decreased in a subset of $\mathrm{PCa}$ as compared to normal prostate, suggesting that Bif-1 may play an important role in the early stage of PCa development, but they also found a proportion of PCa cases that expressed high level of Bif-1 (8). Iacopino et al (19) reported that both BCL-2 and BAX expression levels were higher in PCa than in benign prostatic hyperplasia (BPH) whereas the BCL-2/BAX ratio was lower in $\mathrm{PCa}$ than in $\mathrm{BPH}$, but the Bif-1 level was not analyzed at the same time. Evidence suggests that Bif-1 may be involved in tumorigenesis of $\mathrm{PCa}$, but its effect in the development and progression of PCa remains to be elucidated.

Therefore, to further understand the role of Bif-1 in PCa tumorigenesis, in the present study, we overexpressed Bif-1 by introducing the wild-type Bif-1 gene into an invasive human PCa cell line LNCaP cells, which constitutively expressed very low levels of Bif-1, to assess the possible role of overexpressed Bif-1 on the growth and apoptosis of PCa cells.

\section{Materials and methods}

Cell lines and tissue samples. The PCa cell lines 22RV1, PC3, LNCaP and DU145 were all obtained from the American Type Culture Collection (ATCC; Manassas, VA, USA) and cultured in RPMI-1640 medium (Gibco-BRL, Invitrogen Corporation, Grand Island, NY, USA), $1 \mathrm{mM}$ sodium pyruvate, $100 \mathrm{U} / \mathrm{ml}$ penicillin G, $100 \mu \mathrm{g} / \mathrm{ml}$ streptomycin (Sigma Corporation of America, Ronkonkoma, NY, USA), 10\% fetal bovine serum (FBS; Tianjin HaoYang Biological Manufacture Co., Ltd., Chinese Academy of Sciences, Beijing, China) at $37^{\circ} \mathrm{C}$ in a humidified atmosphere of $5 \% \mathrm{CO}_{2}$.

Prostate tissue samples were collected from 2010-2011 at the Department of Urology, The First Affiliated Hospital of Sun Yat-sen University (Guangzhou, China). In total, 200 samples were collected, including primary PCa $(n=100)$ and benign prostatic hypertrophy samples $(\mathrm{BPH}, \mathrm{n}=100)$. The average age of PCa patients was $70.66 \pm 8.18$, and the average age of $\mathrm{BPH}$ patients was $67.81 \pm 9.31$. The 100 primary $\mathrm{PCa}$ specimens were divided into two categories according to the Gleason score value, Gleason score 4, 5 and $6(n=43)$, and Gleason score 7,8 and $9(n=57)$. All the samples were confirmed by pathologic diagnosis. Prior written consent of each patient for the use of clinical materials for research purposes was obtained, and the approval was granted by the Institutional Ethics Board (IRB) at The First Affiliated Hospital of Sun Yat-sen University.

Construction and transfection of pcDNA3.1(+)-Bif-1 vector. We amplified the full-length gene of wild-type human Bif-1 from human genomic cDNA using forward primer, 5'-CCG GAATTCGCCTAGGATGAATATCATGGAC-3' and reverse primer, 5'-CGCCTCGAGAGTCCACCTACTTAATTGAG CAG-3'. The PCR procedure was: $95^{\circ} \mathrm{C}$ for $3 \mathrm{~min}, 1$ cycle, $95^{\circ} \mathrm{C}$ for $30 \mathrm{sec}, 58^{\circ} \mathrm{C}$ for $30 \mathrm{sec}, 72^{\circ} \mathrm{C}$ for $90 \mathrm{sec}, 35$ cycles, $72^{\circ} \mathrm{C}$, for $5 \mathrm{~min}$. The length of the amplified product was $1,087 \mathrm{bp}$. The cDNA fragments were then cloned into an EcoRI-XhoI double restriction enzyme digested pcDNA3.1(+) vector (Invitrogen, Carlsbad, CA, USA). The selected recombinant plasmids were partially sequenced to confirm a correct Bif-1 open reading frame (ORF). The LNCaP cells were initially seeded at a density of $5 \times 10^{6}$ cells $/ 100 \mathrm{~mm}$ dish $24 \mathrm{~h}$ before transfection. pcDNA3.1(+)-Bif-1 plasmid $(10 \mu \mathrm{g})$ or the empty vector pcDNA3.1(+) control was used to transfect LNCaP cells with Lipofectamine 2000 reagent (Life Technologies, Gaithersburg, MD, USA) according to the manufacturer's instructions. Forty-eight hours after transfection, $0.5 \mathrm{mg} / \mathrm{ml} \mathrm{G} 418$ was added for stable positive clone selection on the basis of preliminary G418 serial test results.

RT-PCR and real-time PCR. RT-PCR was used to confirm the expression of Bif-1 cDNA in pcDNA3.1(+)-Bif-1 recombinant plasmid transfected LNCaP cells, and real-time PCR was used to detect the mRNA levels in PCa cell lines. Briefly, total RNA was extracted from LNCaP cells using TRIzol reagent (Invitrogen) according to the manufacturer's instructions. The isolated total RNA was then mixed with oligo(dT) primer and incubated at $65^{\circ} \mathrm{C}$ for $5 \mathrm{~min}$. Then, cDNA was synthesized using SuperScript III (Invitrogen) at $50^{\circ} \mathrm{C}$ for $50 \mathrm{~min}$ followed by heating at $85^{\circ} \mathrm{C}$ for $5 \mathrm{~min}$. The primers and PCR procedure were the same as those used in Bif-1 cDNA cloning, as shown above. The expected Bif-1 cDNA fragment length was $1,087 \mathrm{bp}$.

To determine relative Bif-1 mRNA expression levels in PCa LNCaP and pcDNA3.1(+)-Bif-1 transfected LNCaP cells, quantitative real-time PCR assays were performed on a Mastercycler EP realplex real-time PCR detector (Eppendorf, Germany). Specific PCR primers were designed based on Bif-1 cDNA gene (GenBank ID, NM_016009). The forward primer sequence was, 5'-GCTTGGCCAGGCTGAGAAG ACAG-3' (nucleotides 417-439), and the reverse primer was, 5'-TCCTGGCATTTGGATTTGGCTGCA-3' (nucleotides 553-530). The amplified product length is $137 \mathrm{bp}$, which corresponds to the ORF of Bif-1. The $\beta$-actin gene (GenBank ID, NM_001101.3) was used as an internal control. The forward primer sequence of $\beta$-actin was, 5'-CAGAGCCTCGC CTTTGCCGATCC-3' (nucleotides 31-53), and its reverse primer was, 5'-CCTTGCACATGCCGGAGCCGT-3' (nucleotides 139-119), with the product length 109 bp. Real-time PCR was carried out using the SYBR Premix Ex Taq ${ }^{\mathrm{TM}}$ kit (Perfect Real-Time; code, DRR081A) (Takara, Dalian, China) in a 
$50 \mu 1$ final volume, containing $25 \mu 1$ of reaction mixture, $0.5 \mu \mathrm{M}$ of the forward and reverse primers, and $3 \mu \mathrm{l}$ of RNA. The real-time PCR procedure was: cycle $1,95^{\circ} \mathrm{C}$ for $3 \mathrm{~min}$; cycle 2 through $35,95^{\circ} \mathrm{C}$ for $5 \mathrm{sec}, 60^{\circ} \mathrm{C}$ for $34 \mathrm{sec}$, and fluorescence signal was detected at the end of each cycle. Melting curve analysis was drawn to confirm the specificity. Detection of each sample was repeated 3 times.

Immunohistochemistry. The slides were dewaxed by heating at $55^{\circ} \mathrm{C}$ for $30 \mathrm{~min}$ followed by 3 washes with xylene, each for $10 \mathrm{~min}$. Tissues were rehydrated by a series of 5-min washes in 100, 95 and $80 \%$ ethanol, and distilled water. Standard cell conditioning [following the Zhongshan Golden Bridge Biotechnology Co., Ltd. (Beijing, China) recommendations] was used for antigen retrieval. Then, the samples were incubated with a Bif-1 goat anti-human antibody (Santa Cruz Biotechnology, Inc., Dallas, TX, USA) with the dilution ratio 1:200 at $4^{\circ} \mathrm{C}$ overnight. The sections were then incubated with biotin-labeled secondary antibody and streptavidin-horseradish peroxidase for $30 \mathrm{~min}$ each (Zhongshan Golden Bridge Biotechnology Co., Ltd.). The samples were developed with 3,3'-diaminobenzidine tetrahydrochloride substrate and counterstained with hematoxylin (both from Zhongshan Golden Bridge Biotechnology Co., Ltd.). The slides were dehydrated and mounted. Negative controls were included by omitting Bif-1 antibody during the primary antibody incubation.

Western blotting. Cultured cells were harvested when $80 \%$ confluent. Cell protein was extracted in a homogenization buffer: phosphate-buffered saline (PBS) containing 1\% Nonidet $\mathrm{P}-40,0.5 \%$ sodium deoxycholate, $0.1 \%$ SDS, $10 \mathrm{mg} / \mathrm{ml}$ phenylmethylsulfonyl fluoride (PMSF), $1 \mathrm{mM}$ sodium orthovanadate, $1 \mu \mathrm{g} / \mathrm{ml}$ leupeptin and $1 \mu \mathrm{g} / \mathrm{ml}$ aprotinin. The protein samples were separated by SDS-polyacrylamide gel electrophoresis (PAGE) and transferred to a nitrocellulose membrane. The membrane was blocked with 5\% skim milk in PBST (pH 7.4 PBS with $0.1 \%$ Tween-20) for $1 \mathrm{~h}$ and incubated with the goat anti-human endophilin B1 polyclonal antibody S-20 (Santa Cruz Biotechnology, Santa Cruz, CA, USA) and the antibody dilution ratio was 1:1,000. The Bif-1 protein was then detected by rabbit anti-goat horseradish peroxidase (HRP)-conjugated secondary antibody (dilution ratio 1:2,000; Santa Cruz Biotechnology) coupled with enhanced chemiluminescence (ECL) western blot detection reagents (Amersham, Arlington, IL, USA). BPH sample BPH1 was used as a control.

Immunofluorescence analysis. Briefly, $1 \times 10^{5}$ cells/well were seeded on a sterile glass coverslip pre-coated with poly-L-lysine (Sigma, St. Louis, MO, USA) in a 6-well culture plate. At $80 \%$ confluence, the cells were washed twice with PBS, fixed by $4 \%$ paraformaldehyde in PBS for $10 \mathrm{~min}$, and permeablized with $0.1 \%$ Triton $\mathrm{X}-100$ in PBS for $10 \mathrm{~min}$ at room temperature. Then, the coverslips were blocked by incubation for $30 \mathrm{~min}$ with 5\% normal goat serum (Jackson Laboratory, Bar Harbor, ME, USA) in PBS. After washing with PBS 3 times, the cells were incubated with goat anti-human endophilin B1 antibody (dilution ratio 1:1,000; Santa Cruz Biotechnology) in PBS in a humidified chamber overnight at $4^{\circ} \mathrm{C}$. After 3 washes by PBS, cells were incubated with FITC-conjugated secondary antibody (1:2,000; Jackson Laboratory) for $1 \mathrm{~h}$ at room temperature. Then, the cells were washed 3 times in PBS, and stained with $1 \mu \mathrm{g} / \mathrm{ml}$ 4',6-diamidino-2-phenylindole (DAPI) for $5 \mathrm{~min}$. After further 3 washes in PBS, the coverslips were sealed with nail polish and observed, or stored in the dark at $4^{\circ} \mathrm{C}$ before observation.

Cell growth assay. For MTT assays, different groups of cells were seeded into 96 -well plates at the density of $2 \times 10^{4}$ cells/well. After 12, 24 and 48 h of culture, 3-(4,5-dimethylthiazol-2-yl)-2,5-diphenyltetrazolium bromide (MTT; Sigma) was added to a final concentration of $0.5 \mathrm{mg} / \mathrm{ml}$ for $4 \mathrm{~h}$ at $37^{\circ} \mathrm{C}$. MTT assays were carried out in 3 duplicate wells for each group, and the absorbance at the wavelength of $570 \mathrm{~nm}$ was measured on a Tecan Sunrise multiwell spectrophotometer (Tecan, Männedorf, Switzerland). The experiments were repeated at least 3 times.

Cell apoptosis analysis. Flow cytometry was used to analyze cell apoptosis. Briefly, cells were cultured in phenol red-free RPMI-1640 medium containing 10\% FBS. Flow cytometric analysis was performed according to the methods of Mendonca et al (21). Briefly, $1 \times 10^{5}$ cells were harvested and washed in PBS twice, then re-suspended in $195 \mu 1$ Annexin V-FITC buffer with $5 \mu 1$ Annexin V-FITC. After 10 min of staining in the dark, cells were washed 3 times with PBS, and re-suspended in $190 \mu \mathrm{l}$ Annexin V-FITC buffer with $10 \mu \mathrm{l}$ of $25 \mu \mathrm{g} / \mathrm{ml}$ propidium iodide. Cells $\left(5 \times 10^{4}\right)$ were used for cell apoptosis analysis by flow cytometric analysis. Each analysis was repeated at least 3 times with similar results.

Wound healing assay. Cell migration was evaluated by a scratched wound-healing assay on plastic plate wells. In brief, cells were seeded into a 6 -well plate $\left(5 \times 10^{5}\right.$ cells/well $)$ and grew to $100 \%$ confluency. The monolayer culture was scratched with a sterile micropipette tip to create a denuded zone (gap) of constant width and the cellular debris was removed. The initial gap width and the residual gap width at 12,24 or $36 \mathrm{~h}$ after wounding were observed under an inverted microscope and photographed. The wound area was measured by the program ImageJ (http://rsb.info.nih.gov/ij/). The percentage of wound closure was estimated by the formula: 1 - (wound area at $\mathrm{Tt} /$ wound area at T0) $\mathrm{x} 100 \%$, where $\mathrm{Tt}$ is the time after wounding and $\mathrm{T} 0$ is the immediately wounding time.

Statistical analysis. Measurement data are presented as the mean \pm SD. Statistical analysis was performed using the unpaired Student's t-test or analysis of variance (ANOVA). A two-sided value of $\mathrm{P}<0.05$ was considered statistically significant. All statistical analyses were performed using SPSS 11.5 software (SPSS, Inc., Chicago, IL, USA).

\section{Results}

Bif-1 expression is downregulated in both PCa cell lines and clinical PCa samples. Bif-1 levels in PCa cells and tissues were detected by real-time PCR and western blot assays. BPH sample (BPH1) served as a control. Real-time PCR results showed that Bif-1 mRNA level was downregulated in $\mathrm{PCa}$ 
A

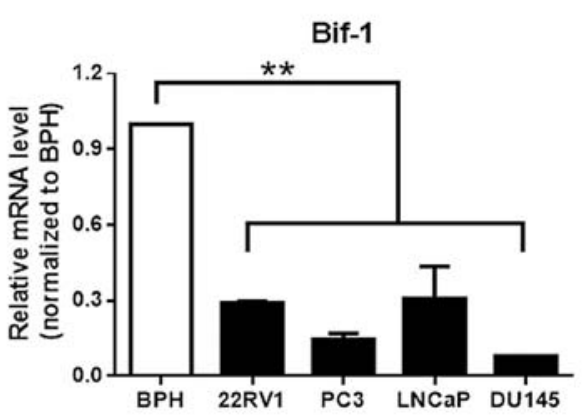

B
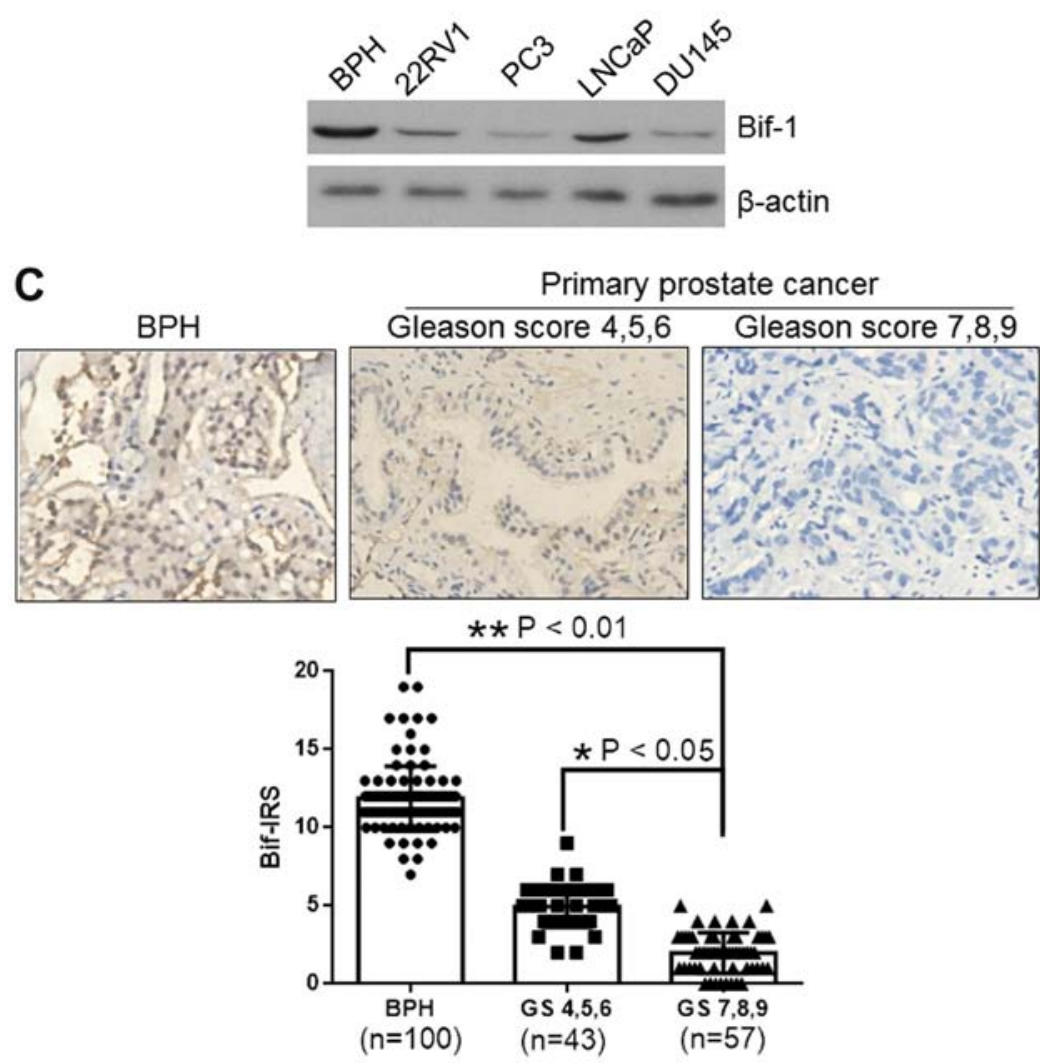

Figure 1. Bif-1 level is downregulated in prostate cancer cells and clinical PCa samples. Bif-1 mRNA levels of prostate cancer cell lines 22RV1, PC3, LNCaP and DU145 were analyzed by real-time PCR and the Bif- 1 protein levels were detected by western blotting, and $\beta$-actin was used as an internal control Bif-1 expression in BPH $(n=100)$ and PCa $(n=100)$ samples was detected by immunohistochemistry and the results were analyzed by immunoreactive score analysis. (A) Bif-1 mRNA expression level was significantly decreased in all the prostate cancer cell lines compared with benign prostatic hypertrophy sample BPH1. (B) Bif-1 protein expression level was markedly suppressed in all the prostate cancer cells lines compared with BPH1. (C) Immunohistochemistry staining of Bif-1 in benign prostatic hyperplasia (BPH) and prostate cancer (PCa) samples, showed that Bif-1 expression is higher in BPH than PCa, and high Gleason-scored PCa samples (Gleason scores 7, 8 and 9, n=57) exhibited significantly lower Bif-1 level than low Gleason-scored PCa samples (Gleason scores 4, 5 and 6, $\mathrm{n}=43$ ). Bif-IRS, Bif-1 immunoreactivity scores; ${ }^{\mathrm{P}} \mathrm{P}<0.05,{ }^{* *} \mathrm{P}<0.01$.

cells 22RV1, PC3, LNCaP and DU145 ( $\mathrm{P}<0.01$ compared with $\mathrm{BPH} 1)$, and western blot analysis of Bif-1 protein expression revealed that Bif-1 protein expression was also decreased in those $\mathrm{PCa}$ cell lines as compared to benign prostate hypertrophy BPH1 (Fig. 1A and B).

To verify the Bif-1 level in PCa samples, we carried out immunohistochemistry in $100 \mathrm{PCa}$ samples and 100 benign prostatic hyperplasia (BPH) samples. The results showed that significant intense nuclear immunoreactivity was seen in BPH tissues and low-grade prostatic carcinoma tissues (Fig. 1C). However, few cells showed positively-stained nuclei in high grade prostatic carcinoma lesions. Immunoreactive score analysis using Student's t-test further confirmed that Bif-1 expression is higher in $\mathrm{BPH}$ than $\mathrm{PCa}(\mathrm{P}<0.01)$, and higher
Gleason-scored samples exhibited significantly lower Bif-1 immunoreactivity scores $(\mathrm{P}<0.05)$. Therefore, Bif-1 expression is suppressed with the cancer progression, as shown in Fig. 1C (BPH vs. high Gleason-scored PCa P<0.01, and low Gleason-scored PCa vs. high Gleason-scored PCa P<0.05). The results confirmed that compared with BPH samples, Bif-1 was significantly suppressed in PCa cells and tissues, and the suppression was more obvious in progressive $\mathrm{PCa}$.

Overexpressed Bif-1 suppresses cell proliferation in $\mathrm{PCa}$ cells. To further understand the role of Bif-1 in PCa development, we constructed an ectopic Bif-1 expression vector, to explore the effect of Bif-1 overexpression on PCa cell behavior. The full-length wild-type human Bif-1 was cloned 
A

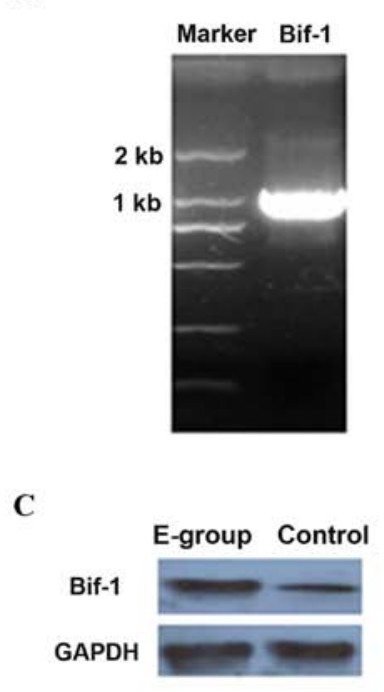

D
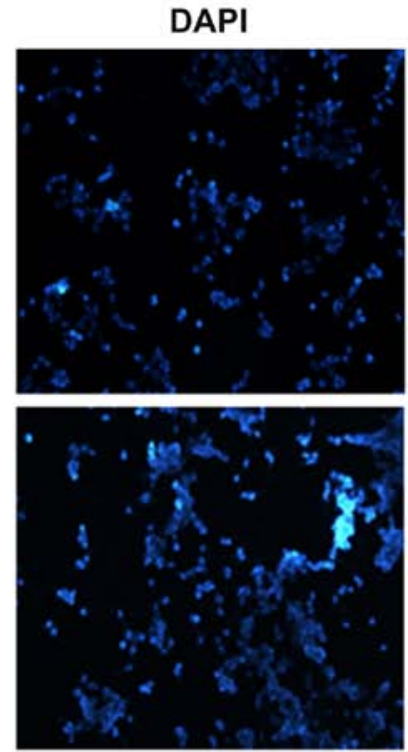

B
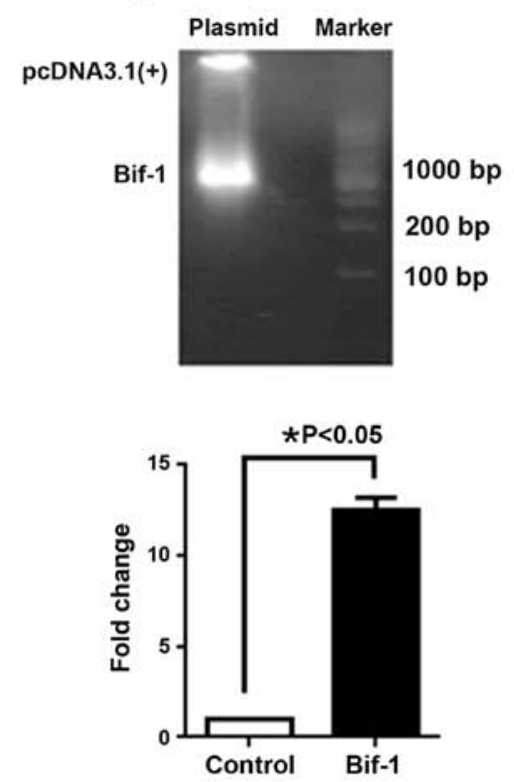

FITC
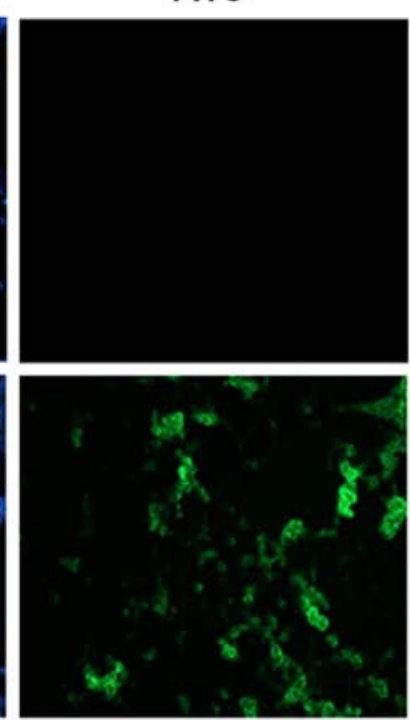

Vector

Bif-1

Figure 2. Construction of pcDNA3.1(+)-Bif-1 expression vector and overexpression of Bif-1 in transfected LNCaP cells. Full length of wild-type human Bif-1 gene was amplified by RT-PCR from human genomic cDNA and inserted into an EcoRI-XhoI double enzyme digested pcDNA3.1(+) vector. Constructed pcDNA3.1(+)-Bif-1 recombinant plasmid was transfected into LNCaP cells by Lipofectamine 2000. The expression level in selected positive clone was identified by real-time PCR and western blotting. (A) The full length of wild-type human Bif-1 cDNA was successfully amplified by RT-PCR from genomic cDNA. The expected product length was 1,087 bp. (B) Identification of pcDNA3.1(+)-Bif-1 plasmid by EcoRI-XhoI double enzyme digestion. The restriction fragment length was 1,087 bp as expected. (C) Western blot analysis and real-time RT-PCR identification of Bif-1 gene expression in transfected LNCaP cells confirmed the successful overexpression of Bif-1. GAPDH served as an internal control. E-group was pCDNA3.1(+)-Bif-1 transfected LNCaP cells and the control group was empty vector pcDNA3.1(+) transfected; " $\mathrm{P}<0.05$. (D) The indirect immunofluorescence staining of Bif-1 protein in pCDNA3.1(+)-Bif-1 plasmid transfected LNCaP cells. Vector control cells and pCDNA3.1(+)-Bif-1 transfected LNCaP cells were in order stained with Bif-1 antibody, FITC-conjugated secondary antibody and DAPI. Cell nucleus showed blue fluorescence and Bif-1 positive cells showed green fluorescence. (Fluorescence inverted microscope, magnification, $\mathrm{x} 100)$.

from human genomic cDNA (Fig. 2A) and the positive recombinant vector was identified by double enzyme digestion and sequencing (Fig. 2B). The pcDNA3.1(+)-Bif-1 expression vector was then transfected into $\mathrm{LNCaP}$ cells and the Bif-1 overexpression cell clones were identified by G418 screening, real-time RT-PCR and western blotting (Fig. 2C). The indirect immunofluorescence staining of Bif-1 also proved that Bif-1 was successfully expressed in pCDNA3.1(+)-Bif-1 plasmid transfected LNCaP cells (Fig. 2D). Stable Bif-1 positive
LNCaP cells were used in the following functional analysis. LNCaP cells transfected with the empty vector pcDNA3.1(+) served as a negative control.

We found that after $24 \mathrm{~h}$ of Bif-1 overexpression, the growth of Bif-1 overexpressing LNCaP cells (E-group) was markedly inhibited, as shown in Fig. 3A, and the growth inhibition effect could be observed even more obviously at $48 \mathrm{~h}$ of Bif- 1 overexpression $(\mathrm{P}<0.05)$. As a contrast, the proliferation of negative control (vector control) and blank 
A

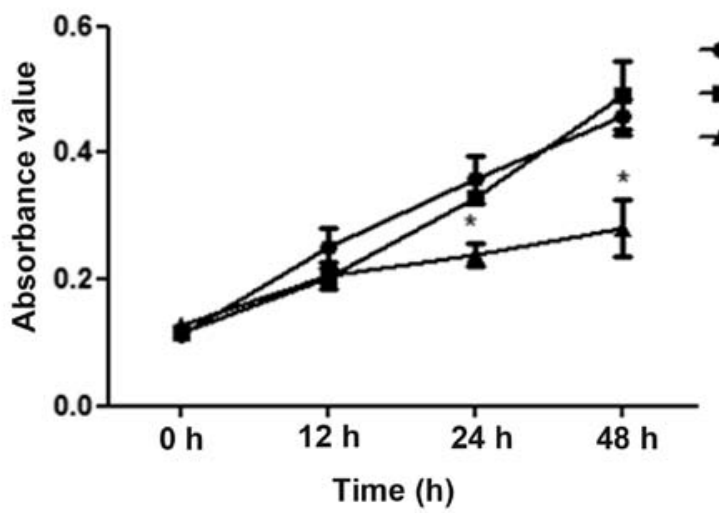

\section{B}

Blank control

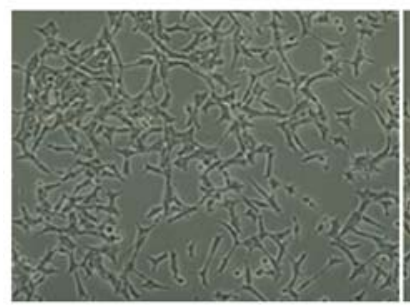

Negative control

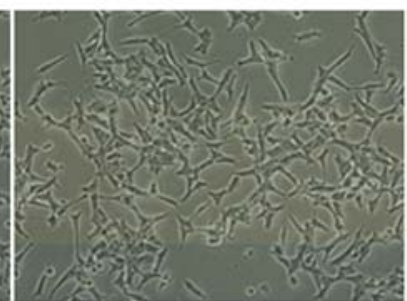

Blank control

Negative control

E-group

Figure 3. Effect of Bif-1 overexpression on LNCaP cell proliferation. Cells/well (2x104) were seeded in triplicate into 96-well culture plates. At 12, 24 and $48 \mathrm{~h}$ of pCDNA3.1(+)-Bif-1 transfection, 3-(4,5-dimethylthiazol-2-yl)-2,5-diphenyltetrazolium bromide (MTT) was added to a final concentration of $5 \mathrm{mg} / \mathrm{ml}$ and incubated for $4 \mathrm{~h}$ at $37^{\circ} \mathrm{C}$, and cell proliferation was analyzed by MTT assay. Absorbance of $570 \mathrm{~nm}$ was measured by a microplate reader at $0,12,24$ and $48 \mathrm{~h}$ after Bif-1 overexpression. Cell morphology was observed at $24 \mathrm{~h}$ of Bif-1 overexpression under a phase contrast microscope. (A) Proliferation of E-group [pCDNA3.1(+)-Bif-1 transfected LNCaP cells], negative group (empty vector transfected LNCaP cells) and blank group (non-transfected LNCaP cells) were analyzed by MTT assay. Cell proliferation of E-group was significantly inhibited after $24 \mathrm{~h}$ of Bif-1 overexpression compared with negative and blank controls; ${ }^{*} \mathrm{P}<0.05$. (B) The appearance of negative and blank controls, and E-group cells at $24 \mathrm{~h}$ after Bif-1 overexpression. Although the number of E-group cells was fewer than negative and blank control cells, cell morphology showed no obvious change. (Inverted phase contrast microscope, magnification, x100).
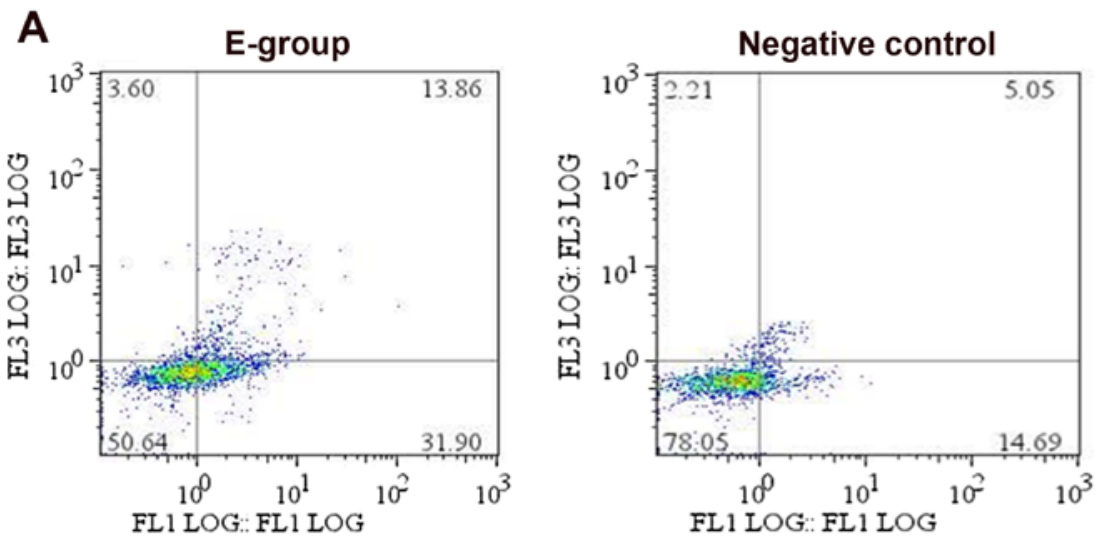

B

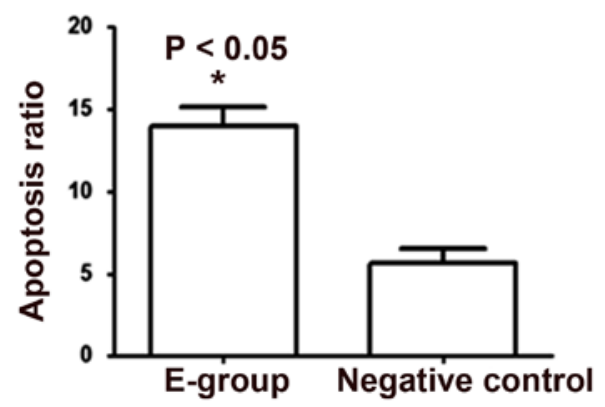

Figure 4. Effect of Bif-1 overexpression on LNCaP cell apoptosis. For each group, $5 \times 10^{4}$ cells were used for cell apoptosis analysis. Cells of E- and negative control groups were stained with Annexin V-FITC followed by propidium iodide and analyzed by flow cytometry. The images were representative of 3 independent experiments with similar results. (A) Flow cytometric analysis showed that the apoptosis proportion of Bif-1 overexpression LNCaP cells (E-group) was higher than that of pCDNA3.1 vector transfected LNCaP cells (negative control). (B) Statistical analysis of the apoptosis difference between E- and negative control group. E-group showed significantly higher apoptosis proportion than the negative control group. 


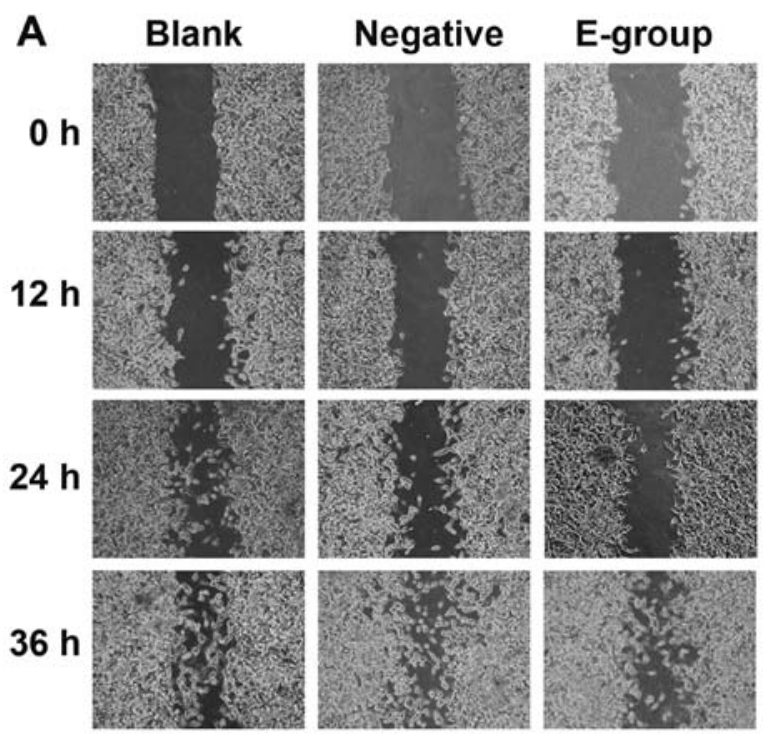

B

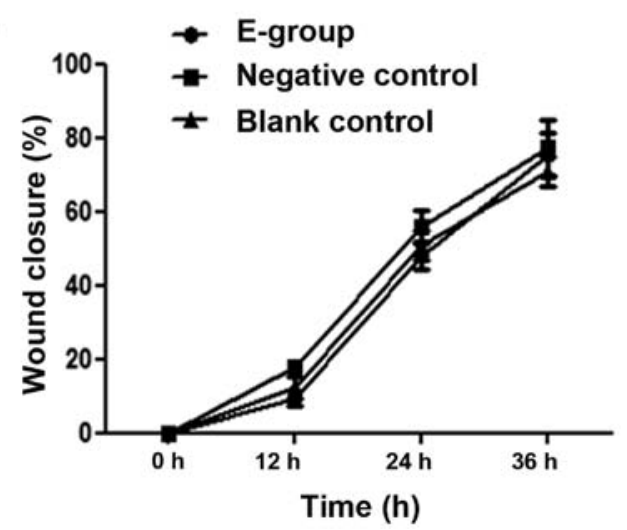

Figure 5. Effect of Bif-1 overexpression on LNCaP cell migration. LNCaP cells were seeded in a 6 -well plate $\left(5 \times 10^{5}\right.$ cells/well) and grew to confluence. The monolayer culture was scratched with a sterile micropipette tip to create a denuded zone (gap) of constant width and the cellular debris was removed by washing. The initial gap width and the residual gap width at 12,24 or $36 \mathrm{~h}$ after wounding were observed and photographed under an inverted microscope. The wound area was measured by the program ImageJ and the percentage of wound closure was calculated. (A) The appearance of blank and negative control, and E-group cells at different time points (inverted phase contrast microscope, magnification, x100). (B) Statistical analysis of cell migration results of E-group and control cells showed that there is no significant differences between the E-group, blank and negative controls as determined by Student's t-test $(\mathrm{P}>0.05)$.

control (non-transfected control) groups was not markedly changed $(\mathrm{P}>0.05)$. Although cell proliferation was significantly inhibited, the morphology of Bif-1 overexpressing LNCaP cells showed no change (Fig. 3B). The results confirmed that Bif-1 could inhibit proliferation of PCa cells, but did not affect the cell morphology.

Bif-1 overexpression promotes cell apoptosis in PCa cells. To further elucidate the molecular mechanism of the proliferation inhibition effect of Bif-1 on PCa cells, we examined the cell apoptosis change in Bif-1 overexpression cells. Flow cytometric analysis showed that, in contrast to the negative control cells, the apoptosis proportion in Bif-1 overexpression LNCaP cells increased from $5.05 \pm 0.87$ to $13.86 \pm 0.29(\mathrm{P}<0.05)$, as shown in Fig. 4. These results proved that Bif-1 overexpression in LNCaP cells induced a significant enhancement of cell apoptosis.

Bif-1 overexpression does not affect the ability of PCa cell migration. To understand the role of Bif-1 overexpression in cell migration, we used wound healing assay to compare the migration ability change between Bif-1 overexpression LNCaP cells (E-group) and the control cells, including the parental LNCaP cells (blank control) and the pCNDA3.1(+) vector transfected cells (negative control). By comparing the difference of the percentage of wound closure between E-group and control groups, we found that there is no significant change between the Bif-1 overexpression LNCaP cells and the control cells ( $\mathrm{P}>0.05$; Fig. 5). Therefore, the wound-healing assay results demonstrated that Bif-1 had no marked effect on prostate cell migration capacity.

\section{Discussion}

Prostate cancer ( $\mathrm{PCa}$ ) is the most frequent malignancy in males and one of the leading causes of cancer-related death among males, particularly in more developed countries (1,2,27-29). Although high-risk locally advanced or metastatic patients who receive androgen deprivation (AD) usually have durable remissions, the cancer cells eventually develop a variety of pathways to survive in a castrate environment and thus making tumor relapse inevitable (27). It has been reported that inhibition of apoptosis is critical in PCa and may contribute to androgen resistance and progression of PCa $(6,9)$. Therefore, to elucidate the mechanisms behind apoptosis escape of $\mathrm{PCa}$ cells is very important for the understanding of PCa progression mechanisms.

BAX interacting factor 1 (Bif-1) is a member of the endophilin B family, which binds to and activates the BAX protein in response to the apoptosis signaling pathway. Recently, mis-regulation of apoptosis has been reported as a new mechanism that may contribute to the progression of $\mathrm{PCa}$ that involves BCL-2 and BAX regulation $(9,19,30)$. Although there is evidence that indicated that Bif-1 may play an important role in the early stage of PCa (8), little is known about its effect on prostate cell biological behavior and its role in $\mathrm{PCa}$ progression remains unclear (8). It has been reported that Bif-1 level is upregulated in a large proportion of PCa cases (8), which seemed inconsistent with the known pro-apoptotic function of Bif-1 $(8,12,13,15,31)$. The relationships between Bif-1 expression and $\mathrm{PCa}$ development are not fully studied and the role of Bif-1 in PCa development remains unclear.

To understand the role of Bif-1 in PCa development, in the present study, we first detected the expression level of Bif-1 in PCa cell lines including 22RV1, PC3, LNCaP and DU145, and found that both Bif-1 gene and protein expression level was decreased in these cell lines compared with benign prostate hypertrophy $(\mathrm{P}<0.01)$. Further immunohistochemistry examinations on clinical $\mathrm{PCa}$ and benign prostate hyperplasia (BPH) samples confirmed that Bif-1 level was higher in $\mathrm{BPH}$, suppressed in low-grade prostatic carcinoma samples $(\mathrm{P}<0.05)$, and significantly decreased in high grade prostatic carcinoma samples $(\mathrm{P}<0.05)$. We presume that the mechanism of downregulated Bif-1 level in progressive $\mathrm{PCa}$ may be related to apoptosis escape of PCa cells in cancer development. 
Our findings are consistent with those of Coppola et al (8). However, Coppola et al (8) also found a proportion of PCa cases that express high level of Bif-1, which we did not find in the present study. Since there is a lack of studies reporting the Bif-1 level in PCa cases, the Bif-1 expression in PCa samples still needs more related studies for complete elucidation.

To explore the relationships between Bif-1 expression level and PCa cell progression, we built a Bif-1 expression vector and Bif-1 overexpression LNCaP cells (E-group). The effect of Bif-1 overexpression on cell apoptosis, proliferation and migration was analyzed by flow cytometry, MTT and would healing assays, respectively. The LNCaP cells were chosen for Bif-1 effect analysis as it was an invasive human $\mathrm{PCa}$ cell line, and expressed constitutively very low levels of Bif-1. It was found that overexpression of Bif-1 significantly inhibited the proliferation of $\mathrm{LNCaP}$ cells $(\mathrm{P}<0.05)$. Although the cell number was markedly reduced, cell morphology was not affected. Further apoptosis analysis by flow cytometry confirmed that Bif-1 could significantly promote cell apoptosis $(\mathrm{P}<0.05)$, which proved that Bif- 1 could inhibit PCa cell proliferation by inducing cell apoptosis. These results are consistent with the known function of proapoptosis of Bif-1 $(12,14)$ and the findings of Iacopino et al $(19)$, and support our presumption that downregulation of Bif-1 may be involved in PCa cell escape of apoptosis, and PCa cells may acquire apoptosis resistance by downregulating Bif-1 expression. However, the PCa apoptosis escape mechanism remains to be interpreted, and further studies are needed to elucidate the signaling pathway that Bif-1 is involved in. In the present study, we reported for the first time that overexpression Bif-1 could significantly inhibit the proliferation by inducing the apoptosis of PCa cells, and our findings also give strong supports of the tumor suppressor functions of Bif-1 in PCa progression. Since Bif-1 promoted apoptosis, inhibited $\mathrm{PCa}$ cell proliferation and acted as a suppressor in $\mathrm{PCa}$ progression, to restore the Bif-1 gene expression may be a new potential strategy for PCa therapy.

We also explored the effect of Bif-1 overexpression on PCa migration, since it was reported that Bif-1 could suppress the migration of breast cancer cells by promoting the EGFR endocytic degradation (20), and whether or not Bif-1 can affect PCa cell migration is still unknown. The wound healing assay showed that Bif-1 overexpression had no significant effect on the migration capacity of PCa cells $(\mathrm{P}>0.05)$. The biological significance of these finding remains to be further determined.

In the present study, we detected the mRNA and protein expression in PCa cell lines, BPH and PCa samples, proved that Bif-1 is downregulated in both PCa cell lines and clinical samples. By introducing the ectopically expressed Bif-1 into LNCaP cells, we evaluated the role of Bif- 1 on the growth and apoptosis of PCa cells. We found that overexpression of Bif-1 could significantly enhance PCa cell apoptosis and inhibit cell proliferation, although it did not affect the migration ability. Our findings give strong evidence that Bif- 1 is involved in $\mathrm{PCa}$ tumorigenesis and act as a suppressor in $\mathrm{PCa}$ progression. To restore the Bif-1 gene expression may be a new potential strategy for PCa therapy. Our findings may have significance in understanding the process of PCa development.

\section{Acknowledgements}

The present study was supported by grants from the National Natural Science Funds of China (nos. 81672556, 81071760 and 30772503).

\section{References}

1. McDavid K, Lee J, Fulton JP, Tonita J, Thompson TD, Ferlay J, Brawley $\mathrm{O}$ and Bray F: Prostate cancer incidence and mortality rates and trends in the United States and Canada. Public Health Rep 119: 174-186, 2004.

2. Bono AV: The global state of prostate cancer: Epidemiology and screening in the second millennium. BJU Int 94 (Suppl 3): S1-S2, 2004.

3. Torre LA, Sauer AM, Chen MS Jr, Kagawa-Singer M, Jemal A and Siegel RL: Cancer statistics for Asian Americans, Native Hawaiians, and Pacific Islanders, 2016: Converging incidence in males and females. CA Cancer J Clin 66: 182-202, 2016.

4. Siegel RL, Miller KD and Jemal A: Cancer statistics, 2016. CA Cancer J Clin 66: 7-30, 2016.

5. Kontos CK, Adamopoulos PG and Scorilas A: Prognostic and predictive biomarkers in prostate cancer. Expert Rev Mol Diagn 15: 1567-1576, 2015.

6. Chao OS and Clément MV: Epidermal growth factor and serum activate distinct pathways to inhibit the $\mathrm{BH} 3$ only protein $\mathrm{BAD}$ in prostate carcinoma LNCaP cells. Oncogene 25: 4458-4469, 2006.

7. Wen S, Niu Y, Lee SO and Chang C: Androgen receptor (AR) positive $v s$ negative roles in prostate cancer cell deaths including apoptosis, anoikis, entosis, necrosis and autophagic cell death. Cancer Treat Rev 40: 31-40, 2014.

8. Coppola D, Oliveri C, Sayegh Z, Boulware D, Takahashi Y, Pow-Sang J, Djeu JY and Wang HG: Bax-interacting factor-1 expression in prostate cancer. Clin Genitourin Cancer 6: 117-121, 2008.

9. Castilla C, Congregado B, Chinchón D, Torrubia FJ, Japón MA and Sáez C: Bcl-xL is overexpressed in hormone-resistant prostate cancer and promotes survival of LNCaP cells via interaction with proapoptotic Bak. Endocrinology 147: 4960-4967, 2006.

10. Shukla S, Fu P and Gupta S: Apigenin induces apoptosis by targeting inhibitor of apoptosis proteins and $\mathrm{Ku} 70$-Bax interaction in prostate cancer. Apoptosis 19: 883-894, 2014.

11. Zhang X, Bi L, Ye Y and Chen J: Formononetin induces apoptosis in PC-3 prostate cancer cells through enhancing the Bax/Bcl-2 ratios and regulating the p38/Akt pathway. Nutr Cancer 66: 656-661, 2014.

12. Takahashi Y, Meyerkord CL and Wang HG: Bif-1/endophilin B1: A candidate for crescent driving force in autophagy. Cell Death Differ 16: 947-955, 2009.

13. Schlauder SM, Calder KB, Khalil FK, Passmore L, Mathew RA and Morgan MB: Bif-1 and Bax expression in cutaneous Merkel cell carcinoma. J Cutan Pathol 36: 21-25, 2009.

14. Cuddeback SM, Yamaguchi H, Komatsu K, Miyashita T, Yamada M, Wu C, Singh S and Wang HG: Molecular cloning and characterization of Bif-1. A novel Src homology 3 domaincontaining protein that associates with Bax. J Biol Chem 276: 20559-20565, 2001.

15. Takahashi Y, Karbowski M, Yamaguchi H, Kazi A, Wu J, Sebti SM, Youle RJ and Wang HG: Loss of Bif-1 suppresses Bax/Bak conformational change and mitochondrial apoptosis. Mol Cell Biol 25: 9369-9382, 2005.

16. Coppola D, Khalil F, Eschrich SA, Boulware D, Yeatman T and Wang HG: Down-regulation of Bax-interacting factor-1 in colorectal adenocarcinoma. Cancer 113: 2665-2670, 2008.

17. Lee JW, Jeong EG, Soung YH, Nam SW, Lee JY, Yoo NJ and Lee SH: Decreased expression of tumour suppressor Bax-interacting factor-1 (Bif-1), a Bax activator, in gastric carcinomas. Pathology 38: 312-315, 2006.

18. Fan R, Miao Y, Shan X, Qian H, Song C, Wu G, Chen Y and Zha W: Bif-1 is overexpressed in hepatocellular carcinoma and correlates with shortened patient survival. Oncol Lett 3: 851-854, 2012.

19. Iacopino F, Angelucci C, Lama G, Zelano G, La Torre G, D'Addessi A, Giovannini C, Bertaccini A, Macaluso MP, Martorana G, et al: Apoptosis-related gene expression in benign prostatic hyperplasia and prostate carcinoma. Anticancer Res 26: 1849-1854, 2006 
20. Runkle KB, Meyerkord CL, Desai NV, Takahashi Y and Wang HG: Bif-1 suppresses breast cancer cell migration by promoting EGFR endocytic degradation. Cancer Biol Ther 13: 956-966, 2012.

21. Mendonca MS, Howard KL, Farrington DL, Desmond LA, Temples TM, Mayhugh BM, Pink JJ and Boothman DA: Delayed apoptotic responses associated with radiation-induced neoplastic transformation of human hybrid cells. Cancer Res 59: 3972-3979, 1999.

22. Bonner AE, Lemon WJ, Devereux TR, Lubet RA and You M: Molecular profiling of mouse lung tumors: Association with tumor progression, lung development, and human lung adenocarcinomas. Oncogene 23: 1166-1176, 2004.

23. Coppola D, Helm J, Ghayouri M, Malafa MP and Wang HG: Down-regulation of Bax-interacting factor 1 in human pancreatic ductal adenocarcinoma. Pancreas 40: 433-437, 2011.

24. Ho J, Kong JW, Choong LY, Loh MC, Toy W, Chong PK, Wong CH, Wong CY, Shah N and Lim YP: Novel breast cancer metastasis-associated proteins. J Proteome Res 8: 583-594, 2009.

25. Ko YH, Cho YS, Won HS, An HJ, Sun DS, Hong SU, Park JH and Lee MA: Stage-stratified analysis of prognostic significance of Bax-interacting factor-1 expression in resected colorectal cancer. Biomed Res Int 2013: 329839, 2013.
26. Kim SY, Oh YL, Kim KM, Jeong EG, Kim MS, Yoo NJ and Lee SH: Decreased expression of Bax-interacting factor-1 (Bif-1) in invasive urinary bladder and gallbladder cancers. Pathology 40: 553-557, 2008.

27. Hoimes CJ and Kelly WK: Redefining hormone resistance in prostate cancer. Ther Adv Med Oncol 2: 107-123, 2010.

28. Center MM, Jemal A, Lortet-Tieulent J, Ward E, Ferlay J, Brawley $\mathrm{O}$ and Bray $\mathrm{F}$ : International variation in prostate cancer incidence and mortality rates. Eur Urol 61: 1079-1092, 2012.

29. Siegel RL, Miller KD and Jemal A: Cancer statistics, 2015. CA Cancer J Clin 65: 5-29, 2015.

30. Wang DB, Uo T, Kinoshita C, Sopher BL, Lee RJ, Murphy SP, Kinoshita Y, Garden GA, Wang HG and Morrison RS: Bax interacting factor-1 promotes survival and mitochondrial elongation in neurons. J Neurosci 34: 2674-2683, 2014.

31. Yang J, Takahashi Y, Cheng E, Liu J, Terranova PF, Zhao B Thrasher JB, Wang HG and Li B: GSK-3beta promotes cell survival by modulating Bif-1-dependent autophagy and cell death. J Cell Sci 123: 861-870, 2010. 